\title{
Expression of genes involved in the embryo-maternal interaction in the early-pregnant canine uterus
}

\author{
E Kautz, A Gram, S Aslan, S S Ay², M Selçuk ${ }^{3}, \mathrm{H} K a n c a^{1}$, E Koldaş ${ }^{2}$ E Akal ${ }^{3}$, K Karakaş $^{1}$, \\ $M$ Findik $^{2}$, A Boos and M P Kowalewski \\ Institute of Veterinary Anatomy, Vetsuisse Faculty, University of Zurich, Winterthurerstrasse 260, CH-8057 Zurich, \\ Switzerland, ${ }^{1}$ Department of Obstetrics and Gynaecology, Faculty of Veterinary Medicine, University of Ankara, \\ Ankara, Turkey, Departments of ${ }^{2}$ Obstetrics and Gynaecology and ${ }^{3}$ Reproduction and Artificial Insemination, \\ Faculty of Veterinary Medicine, University of Ondokuz Mayis, Samsun, Turkey
}

Correspondence should be addressed to M P Kowalewski; Email: kowalewskipl@yahoo.de or kowalewski@vetanat.uzh.ch

\begin{abstract}
Although there is no acute luteolytic mechanism in the absence of pregnancy in the bitch, a precise and well-timed embryo-maternal interaction seems to be required for the initiation and maintenance of gestation. As only limited information is available about these processes in dogs, in this study, the uterine expression of possible decidualization markers was investigated during the pre-implantation stage (days 10-12) of pregnancy and in the corresponding nonpregnant controls. In addition, the expression of selected genes associated with blastocyst development and/or implantation was investigated in embryos flushed from the uteri of bitches used for this study (unhatched and hatched blastocysts). There was an upregulated expression of prolactin receptor (PRLR) and IGF2 observed pre-implantation. The expression of $P R L$ and of IGF1 was unaffected, and neither was the expression of progesterone- or estrogen receptor $\beta$ (ESR2). In contrast, (ESR1) levels were elevated during early pregnancy. Prostaglandin (PG)-system revealed upregulated expression of PGE2-synthase and its receptors, PTGER2 and PTGER4, and of the PG-transporter. Elevated levels of AKR1C3 mRNA, but not the protein itself, were noted. Expression of prostaglandin-endoperoxide synthase 2 (PTGS2) remained unaffected. Most of the transcripts were predominantly localized to the uterine epithelial cells, myometrium and, to a lesser extent, to the uterine stroma. PGES (PTGES) mRNA was abundantly expressed in both groups of embryos and appeared higher in the hatched ones. The expression level of IGF2 mRNA appeared higher than that of IGF1 mRNA in hatched embryos. In unhatched embryos IGF1, IGF2, and PTGS2 mRNA levels were below the detection limit.

Reproduction (2014) 147 703-717
\end{abstract}

\section{Introduction}

Establishment and maintenance of pregnancy require synthesis and well-orchestrated secretion of a plethora of regulatory factors that establish the uterine milieu needed for embryo implantation and development. The vast majority of these factors remain under the control of progesterone, which is an essential pleiotropic regulator of uterine function.

Because there is no placental steroidogenic activity in the dog, the provision of circulating progesterone depends on corpora lutea $(\mathrm{CL})$ as the major source of this hormone throughout gestation (Concannon et al. 1989). In livestock, e.g., cattle, pigs, and horses, it is well established that uterine prostaglandin $\mathrm{F} 2 \alpha(\mathrm{PGF} 2 \alpha)$ is luteolytic and is responsible for terminating the luteal phase of the estrous cycle in nonpregnant females; therefore, there is no pseudopregnancy in these animals. In contrast to livestock, at least in nonpregnant bitches, there is no uterine luteolysin that could be required for normal ovarian cyclicity, because normal ovarian function is observed following hysterectomy (Olson et al. 1984, Hoffmann et al. 1992). Furthermore, a luteolytic role of intraluteally produced prostaglandins (PGs) can be ruled out (Kowalewski et al. 2006a, 2009). Thus, the absence of an acute luteolytic mechanism in the nonpregnant bitch (Concannon et al. 1989, Hoffmann et al. 1992) results in a physiological pseudopregnancy and a luteal life span similar to, or even longer than, that observed in pregnant bitches. In contrast, in pregnant bitches, the steep prepartum progesterone decline is associated with strongly increased PGF $2 \alpha$ concentrations in the maternal circulation (Nohr et al. 1993), implying its role during prepartum luteolysis and/ or parturition.

Prostaglandin E2 (PGE2) is one of the important luteotropic factors in the dog (Kowalewski et al. 2008, 
2009, 2013). As recently shown, PGE2 is capable of activating progesterone synthesis in canine luteal cells isolated from early developing $\mathrm{CL}$ acting at the level of STAR protein expression and function (Kowalewski et al. 2013). Although both luteinizing hormone (LH) and prolactin (PRL) are luteotropic factors, with PRL being the predominant one (Concannon 1980, Okkens et al. 1990, Onclin et al. 1993, 2000), gonadotropic support does not seem to be required for luteal maintenance during the early-CL phase (Okkens et al. 1986).

Consequently, the canine $\mathrm{CL}$ seems to possess an inherent life span, resulting in a similar progesterone secretion pattern in pregnant and nonpregnant animals that is mirrored in circulating progesterone levels that do not differ significantly until shortly before parturition; at that time, when a dramatic prepartum progesterone decline is observed, signaling the onset of parturition (Concannon et al. 1989). This hormone profile precludes progesterone as a usable marker for detection of pregnancy in the bitch. Moreover, no pregnancyassociated increase in estrogens is observed in the dog (Hoffmann et al. 1994).

Even though knowledge concerning the endocrine control of the canine reproductive cycle has greatly improved, there is still a lack of information concerning the progesterone-dependent establishment of the intimate, initial embryo-maternal contact and the role of the early canine embryo during this process. In particular, knowledge about endocrine mechanisms regulating the uterine microenvironment before implantation is still limited for the dog. This aspect is important for the entire early gestational period, up until days 17-18 after mating, at which time implantation takes place in dogs, immediately followed by the start of placenta formation (Amoroso 1952).

Before that, the progesterone-dependent decidualization process starts, which is characterized by a very strong, species-specific remodeling of the uterine tissues, especially at the implantation sites. As a result of this change, maternal stroma-derived, so-called decidual cells, are the only cells of the canine placenta expressing the progesterone receptor (PGR; Vermeirsch et al. 2000, Kowalewski et al. 2010). Interfering with PGR function, e.g., by application of an anti-gestagen, will unequivocally lead to preterm parturition/abortion (Baan et al. 2008, Kowalewski et al. 2010).

In some earlier studies aimed at detecting factors possibly contributing to embryo implantation in the dog, no differences were found in the expression of heatshock proteins and acute phase proteins between the uteri of early-pregnant and nonpregnant dogs (Evans \& Anderton 1992, Buhi et al. 1993, Concannon et al. 1996). Recently, CD8, IL4 and IFN $\gamma$ mRNA were found as being abundantly expressed in the early-pregnant uterus, while the expression of CD4, TNF and IL6 mRNA seemed to be targeted to the nonpregnant uterus (Schafer-Somi et al. 2008, Beceriklisoy et al. 2009). In contrast to insulin-like growth factor 1 (IGF1), the expression of IGF2 mRNA was found both during early pregnancy and in the nonpregnant uterus (Schafer-Somi et al. 2008). Even though these data, which are mostly based on qualitative transcriptional analysis studies, still need further confirmation, they indicate the differential regulation of the uterine function in the pregnant vs nonpregnant dogs and suggest a possible role of the pre-implantation embryo in this process.

Together with IGF1 and 2, the increased endometrial expression of PRL belongs to the so-called markers of decidualization (Irwin et al. 1994, Ramathal et al. 2010). Recently (Kowalewski et al. 2011a), we have speculated that PRL acting through endo- and/or paracrine mechanisms might be involved in endometrial glandular secretory function in the dog. Furthermore, Bukowska et al. (2011) reported an increased expression of ITGA2B, ITGB2, and ITGB3 and of VEGF $-165,-182$, and -188 in the uterus of earlypregnant bitches.

Nevertheless, the factors and endocrine pathways regulating the functions of the pregnant uterus during the onset of canine pregnancy require further elucidation. Improving our knowledge about the establishment and composition of the proper uterine pre-implantation milieu could improve understanding of the etiopathogenesis of some frequently occurring diestrual disorders of the uterus, such as endometrial hyperplasia complex. This disorder seems to originate from a dysregulated endocrinological response of the uterus to hormonal stimulation during the luteal phase of the estrous cycle and is considered by many authors as an initial phase in the development of pyometra. Furthermore, the poor outcome of IVF procedures in canids may also be related to an inappropriate environment for oocyte maturation, lacking growth factors required for the acquisition of full embryo developmental competence (Luvoni et al. 2006).

Consequently, the expression and cellular localization of several genes that are possibly differentially regulated during canine early pregnancy, including the so-called decidualization markers, were investigated during the pre-implantation stage of pregnancy and in corresponding uterine tissues from nonpregnant dogs. During this early stage of pregnancy, the survival and development of free-floating embryos are dependent on the intrauterine environment. The expression of $\mathrm{CDH} 1$, a cell adhesion protein, whose decreased expression is frequently associated with increased migratory activity of different cell types, was also evaluated. In addition, while limited by availability of the experimental material, the expression of selected genes was investigated when possible in embryos flushed from the earlypregnant uteri of bitches used for this study. 


\section{Materials and methods}

\section{Tissue collections}

Uterine tissues from eight $(n=8)$ early-pregnant (preimplantation group, days 10-12 of pregnancy), crossbreed, healthy bitches were used for this study. The day of mating (day 0) was 2-3 days after ovulation, which was determined by vaginal cytology and by progesterone measurements (>5 ng/ml in peripheral blood). The pre-implantation stage of pregnancy was confirmed by flushing embryos from uteri. Dogs determined as nonpregnant in the uterine flushings served as negative controls $(n=6)$. Uterine samples were collected via ovariohysterectomy. All experimental procedures were carried out in accordance with animal welfare legislation.

For the isolation of RNA, immediately after surgery, uterine tissues (including all anatomical layers) were trimmed of surrounding connective tissues and shock-frozen in liquid nitrogen; longer storage was at $-80^{\circ} \mathrm{C}$.

For immunohistochemistry (IHC) and in situ hybridization (ISH), after surgery tissue samples were fixed for $24 \mathrm{~h}$ at $+4{ }^{\circ} \mathrm{C}$ in $10 \%$ neutral phosphate buffered formalin. Afterwards, they were washed daily with PBS for one week, subsequently dehydrated in a graded ethanol series, and embedded in paraffin-equivalent HistoComp (Vogel, Giessen, Germany).

In addition, embryos sampled from five uteri $(n=19)$ were available for this study. After careful evaluation under a stereomicroscope, embryos were classified into two groups: hatched blastocysts $(n=12,63 \%)$ and unhatched blastocysts $(n=7,37 \%)$, and immediately frozen and stored at $-80{ }^{\circ} \mathrm{C}$.

\section{RNA isolation and reverse transcription (RT)}

TRIZOL reagent (Invitrogen) was used following the manufacturer's protocol in order to isolate total RNA from all samples investigated. The RNA content was measured with a NanoDrop 2000 u.v.-Vis Spectrophotometer (Thermo Scientific, Wilmington, DE, USA).

For further purification of the RNA content, DNase treatment with RQ1 RNAse-free DNAse (Promega) was carried out following the manufacturer's instructions. For each sample, 100-200 ng DNase-treated total RNA were used in the RT, and cDNA was synthesized using RT reagents purchased from Applied Biosystems, with random hexamers used as primers according to our previously published protocol (Kowalewski et al. 2006a, 2011a). All reactions were carried out in an Eppendorf Mastercycler (Vaudaux-Eppendorf AG, Basel, $\mathrm{CH}$, Switzerland). The following RT conditions were applied: $8 \mathrm{~min}$ at $21^{\circ} \mathrm{C}$, then $15 \mathrm{~min}$ at $42{ }^{\circ} \mathrm{C}$, after which the reaction was stopped by incubation for $5 \mathrm{~min}$ at $99^{\circ} \mathrm{C}$.

\section{Homology cloning of canine-specific IGF1R}

The canine-specific IGF1R cDNA had not been characterized before this study. Thus, to provide required data on the mRNA level, molecular cloning and sequencing were carried out. Using an online available predicted sequence, canine-specific $I G F 1 R$ primers were designed and ordered from Microsynth
AG (Balgach, $\mathrm{CH}$, Switzerland): forward 5'-CTC GAC AAC CAG AAC TTG C-3' and reverse 5'-GTT GTG GCG GTA AAG GTA AC-3'.

The GeneAmp Gold RNA PCR Kit from Applied Biosystems was used in a hot-start PCR according to our previously described protocol (Kowalewski et al. 2006a, 2011a). The annealing temperature was $58{ }^{\circ} \mathrm{C}$. Total RNA obtained from at least three uterine samples was used, and PCR fragments comprising 717 bp of partial canine IGF1R were successfully amplified. The following negative controls were run for each experiment: autoclaved water used instead of cDNA (no template control) and the so-called RT-minus control, i.e., samples in which no RT reaction was carried out. The PCR products were separated on a $2 \%$ ethidium bromidestained agarose gel extracted using a Qiaex II gel extraction system (Qiagen $\mathrm{GmbH}$ ), subcloned into pGEM-T vector (Promega), and transformed and amplified in XL1 Blue competent cells (Stratagene, La Jolla, CA, USA). After being purified with Pure Yield Plasmid MidiPrep System (Promega), bacterial plasmids were sequenced on both strands with T7 and Sp6 primers (Microsynth). Finally, the cloned sequence was submitted to GenBank with the following accession number: KF793925.

\section{Real-time (TaqMan) PCR and data evaluation}

Real-time (TaqMan) PCR analysis was carried out in an automated fluorometer ABI PRISM 7500 Sequence Detection System (Applied Biosystems), in accordance with the manufacturer's instructions and following our previously described protocol (Kowalewski et al. 2010, 2011b). The cDNA synthesis and negative controls were as described earlier for qualitative PCR. Fast Start Universal Probe Master (ROX) (Roche Diagnostics AG) was used. The semi-quantitation of target gene expression was performed using three independent endogenous reference genes (GAPDH, 18SrRNA, and cyclophilin $\mathrm{A})$ in the comparative $C T$ method ( $\Delta \Delta C \mathrm{~T}$ method) as described previously (Kowalewski et al. 2010, 2011b) and according to the ABI 7500 Fast Real-Time PCR System manufacturer's protocol. The efficiencies of the PCR assays were established by the CT slope method assuring $\sim 100 \%$ reaction efficiency. Selected PCR products were sent for sequencing (Microsynth). Primers and 6-carboxyfluorescein (6-FAM) and 6-carboxytetramethylrhodamine (TAMRA)labeled TaqMan probes, provided by Microsynth, are listed in Table 1. The following canine-specific TaqMan Gene Expression Assays are commercially available and purchased from Applied Biosystems: cyclophilin A (Prod. No. Cf03986523-gH), CDH1 (Prod. No. Cf02624268_m1), IGF1 (Prod. No. Cf02627846_m1), and IGF2 (Prod. No. Cf02647136_m1).

An unpaired, two-tailed Student's t-test was performed to compare the levels of target genes in uterine samples from early-pregnant and nonpregnant control dogs. Numerical data are presented as the mean \pm s.D. Due to the uneven distribution of the RT-PCR data obtained for the expression of $L H R, I G F 1 R$ and $O T R$, results are presented as geometric means with deviation factor $\left(\mathrm{Xg}\right.$. DF $\left.{ }^{ \pm 1}\right)$. The statistical software program 
Table 1 List of primers and TaqMan probes used for the semi-quantitative RT-PCR.

\begin{tabular}{|c|c|c|c|}
\hline Primer & $\begin{array}{l}\text { Accession } \\
\text { numbers }\end{array}$ & Primer sequence & $\begin{array}{l}\text { Product } \\
\text { lenght (bp) }\end{array}$ \\
\hline GAPDH & AB028142 & $\begin{array}{l}\text { Forward: 5'-GCT GCCAAATAT GACGACATC A-3' } \\
\text { Reverse: 5'-GTA GCC CAG GAT GCC TTT GAG-3' } \\
\text { TaqMan probe: 5'-TCC CTC CGA TGC CTG CTT CAC TAC CTT-3' }\end{array}$ & 75 \\
\hline $18 S r R N A$ & FJ797658 & $\begin{array}{l}\text { Forward: } 5^{\prime}-\text { GTC GCT CGC TCC TCT CCT ACT-3' } \\
\text { Reverse: } 5^{\prime} \text {-GGC TGA CCG GGT TGG TTT-3' } \\
\text { TaqMan probe: } 5^{\prime} \text {-ACA TGC CGA CGG GCG CTG AC-3' }\end{array}$ & 125 \\
\hline IGF1R & XM545828 & $\begin{array}{l}\text { Forward: 5'-GGA CGT TGA GCC TGG CAT T-3' } \\
\text { Reverse: 5'-CAC TCT TAG CCC CAC GGA TGT-3' } \\
\text { TaqMan probe: 5'-AGC CCT GGA CGC AGT ATG CGG-3' }\end{array}$ & 119 \\
\hline$P R L R$ & HQ267784 & $\begin{array}{l}\text { Forward: 5'-GGA TCT TTG TGG CCG TTC TTT-3' } \\
\text { Reverse: 5'-AAG GAT GCA GGT CAC CAT GCT AT-3' } \\
\text { TaqMan probe: 5'-ATT ATG GTC GTA GCA GTG GCT TTG AAA GGC-3' }\end{array}$ & 92 \\
\hline$P R L$ & NM_00108275 & $\begin{array}{l}\text { Forward: } 5^{\prime} \text {-CAA GCC CAA CAG ATC CAC CAT-3' } \\
\text { Reverse: } 5^{\prime} \text {-ATC CCC CGC ACT TCT GTG A-3' } \\
\text { TaqMan probe: } 5^{\prime} \text {-CTG AGG GTG CTG CGC TCC TGG-3' }\end{array}$ & 104 \\
\hline$P G R$ & NM_001003074 & $\begin{array}{l}\text { Forward: } 5^{\prime} \text {-CGA GTC ATT ACC TCA GAA GAT TTG TTT-3' } \\
\text { Reverse: } 5^{\prime} \text {-CTT CCA TTG CCC TTT TAA AGA AGA-3' } \\
\text { TaqMan probe: } 5^{\prime} \text {-AAG CAT CAG GCT GTC ATT ATG GTG TCC TAA CTT-3' }\end{array}$ & 113 \\
\hline ESR1 & XM533454 & $\begin{array}{l}\text { Forward: } 5^{\prime} \text {-CCC ATG GAG GAG ACA AAC CA-3' } \\
\text { Reverse: } 5^{\prime} \text {-CCC TGC CTC CTC GGT GAT ATA-3' } \\
\text { TaqMan probe: } 5^{\prime} \text {-CAC GGG CCC AAC TTC ATC ACA TTC C-3' }\end{array}$ & 93 \\
\hline ESR2 & XM861041 & $\begin{array}{l}\text { Forward: } 5^{\prime} \text {-CCC AGC ACG CCC TTC A-3' } \\
\text { Reverse: 5'-AAT CAT ATG CAC GAG TTC CTT GTC-3' } \\
\text { TaqMan probe: } 5^{\prime} \text {-CCT CCA TGA TGA TGT CCC TGA CC-3' }\end{array}$ & 78 \\
\hline PTGS2 & HQ110882 & $\begin{array}{l}\text { Forward: 5'-GGA GCA TAA CAG AGT GTG TGA TGT G-3' } \\
\text { Reverse: 5'-AAG TAT TAG CCT GCT CGT CTG GAA T-3' } \\
\text { TaqMan probe: 5'-CGC TCA TCA TCC CAT TCT GGG TGC-3' }\end{array}$ & 87 \\
\hline AKR1C3 & NM_001012344 & $\begin{array}{l}\text { Forward: } 5^{\prime} \text {-AGG GCT TGC CAA GTC TAT TGG-3' } \\
\text { Reverse: 5'-GCC TTG GCT TGC TCA GGA T-3' } \\
\text { TaqMan probe: } 5^{\prime} \text {-TCC AAC TTT AAC CGC AGG CAG CTG G-3' }\end{array}$ & 74 \\
\hline PTGES & NM_001122854 & $\begin{array}{l}\text { Forward: } 5^{\prime} \text {-GTC CTG GCG CTG GTG AGT-3' } \\
\text { Reverse: 5'-ATG ACA GCC ACC ACG TAC ATC T-3' } \\
\text { TaqMan probe: } 5^{\prime} \text {-TCC CAG CCT TCC TGC TCT GCA GC-3' }\end{array}$ & 89 \\
\hline PTGFR (FP) & NM_001048097 & $\begin{array}{l}\text { Forward: } 5^{\prime} \text {-ACC AGT CGA ACA TCC TTT GCA-3' } \\
\text { Reverse: } 5^{\prime} \text {-GGC CAT CAC ACT GCC TAG AAA-3' } \\
\text { TaqMan probe: 5'-CAT GGT GTT CTC CGG TCT GTG CCC-3' }\end{array}$ & 86 \\
\hline PTGER2 & AF075602 & $\begin{array}{l}\text { Forward: } 5^{\prime} \text {-CAC CCT GCT GCT GCT TCT C-3' } \\
\text { Reverse: } 5^{\prime} \text {-CGG TGC ATG CGG ATG AG-3' } \\
\text { TaqMan probe: } 5^{\prime} \text {-TGC TCG CCT GCA ACT TTC AGC GTC-3' }\end{array}$ & 78 \\
\hline PTGER4 & NM_001003054 & $\begin{array}{l}\text { Forward: 5'-AAA TCA GCA AAA ACC CAG ACT TG-3' } \\
\text { Reverse: 5'-GCA CGG TCT TCC GCA GAA-3' } \\
\text { TaqMan probe: 5'-ATCCGA ATT GCT GCT GTG AAC CCT ATC C-3' }\end{array}$ & 96 \\
\hline SLCO2A1 & NM_001011558 & $\begin{array}{l}\text { Forward: } 5^{\prime} \text {-TGC AGC ACT AGG AAT GCT GTT C-3' } \\
\text { Reverse: 5'-GGG CGC AGA GAA TCA TGG A-3' } \\
\text { TaqMan probe: } 5^{\prime} \text {-TCT GCA AAC CAT TCC CCG CGT G-3' }\end{array}$ & 116 \\
\hline HPGD & NM_001284477 & $\begin{array}{l}\text { Forward: 5'-GGC AGC GAA TCT CAT GAA CAG-3' } \\
\text { Reverse: 5'-TCT TCT TTC TCA ATG GAT TCA AGGA-3' } \\
\text { TaqMan probe: 5'-TGA ATG CCA TTT GCC CAG GCT TTG-3' }\end{array}$ & 93 \\
\hline OTR & NM_001198659 & $\begin{array}{l}\text { Forward: 5'-GGA TCA CGC TCT CCG TCT ACA-3' } \\
\text { Reverse: 5'-CGT CTT GAG TCG CAG GTT CTG-3' } \\
\text { TaqMan probe: 5'-CCT GCT ACG GCC TCA TCA GCT TCA A-3' }\end{array}$ & 98 \\
\hline$L H R$ & XM538486 & $\begin{array}{l}\text { Forward: } 5^{\prime} \text {-TCA TCA TTT GTG CTT GCT ACA TTA AA-3' } \\
\text { Reverse: } 5^{\prime} \text {-CGC CAT TTT CTT AGC AAT CTT TG-3' } \\
\text { TagMan probe: } 5^{\prime} \text {-TGC AGT TCA AAA TCC AGA GCT GAT GGC-3' }\end{array}$ & 98 \\
\hline
\end{tabular}

GraphPad 3.06 (GraphPad Software, San Diego, CA, USA) was used. $P<0.05$ was considered statistically significant.

\section{Immunohistochemistry (IHC)}

Formalin-fixed, paraffin-embedded uterine cross-sections (2-3 $\mu \mathrm{m}$ thick) from early-pregnant and nonpregnant bitches, mounted on SuperFrost Plus microscope slides (Menzel-Gläser, Braunschweig, Germany), were subjected to the standard immunoperoxidase detection method following our previously described protocol (Kowalewski et al. 2006b, 2010, Gram et al. 2013a). The list of primary antibodies and of the respective IgG irrelevant antibodies (negative/isotype controls) is presented in Table 2. Following biotinylated secondary antibodies were used (all at 1:100 dilution): horse anti mouse IgG BA-2000, goat antiguinea pig IgG BA-7000, goat anti rabbit IgG BA-1000 and horse anti goat IgG BA-9500, all from Vector Laboratories Inc. (Burlingame, CA, USA). Additionally, slides omitting the 


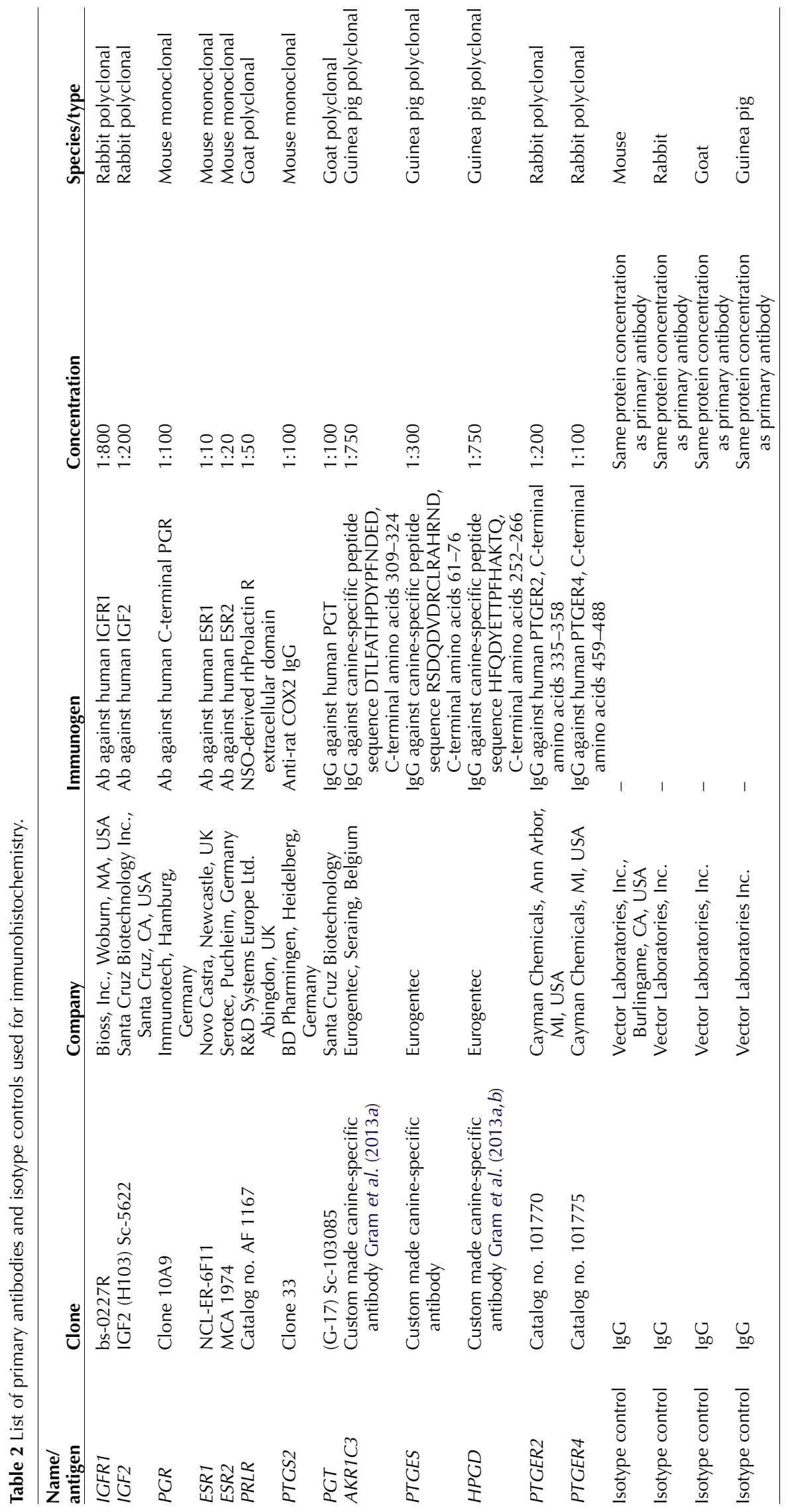



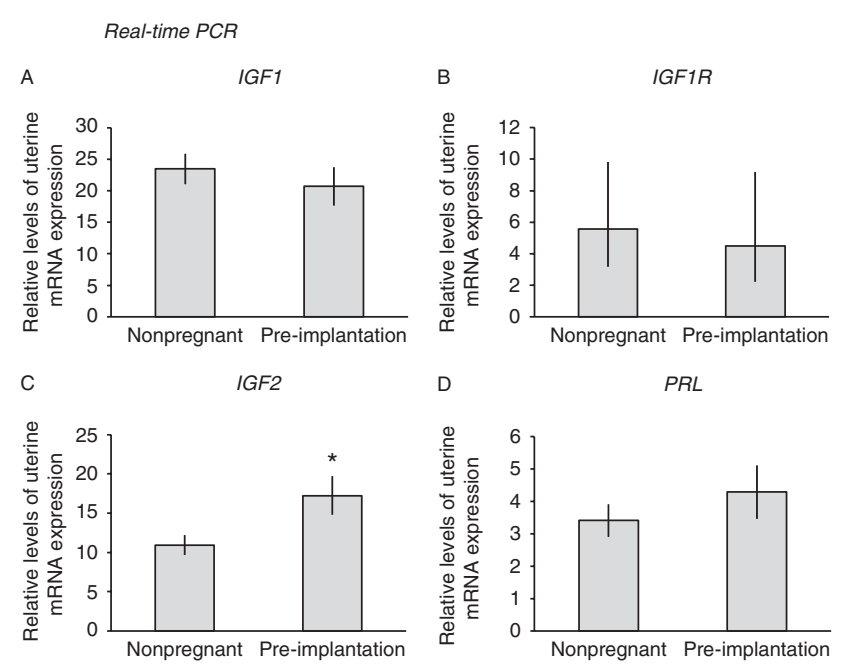

$\mathrm{E}$
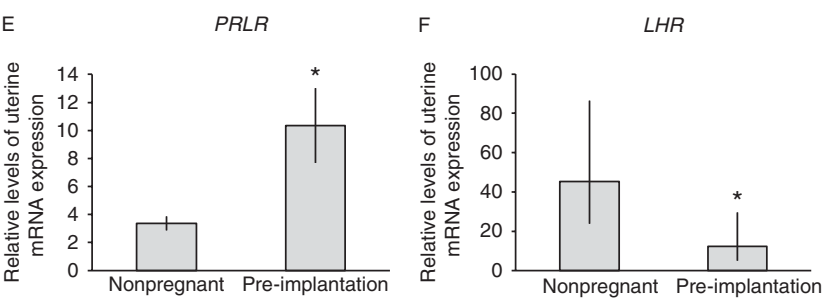

Figure 1 Expression of IGF1, IGF2, IGF1R, PRL and its receptor (PRLR), and $L H R$ as determined by Real Time (TaqMan) PCR in uterine samples from early-pregnant uterus (pre-implantation; embryo-induced effects), and its nonpregnant counterparts. Numerical data are presented either as the mean \pm s.D. $(A, C, D$, and $E)$, or as geometric means with deviation factor $\left(\mathrm{Xg} . \mathrm{DF}^{ \pm} 1\right)(\mathrm{B}$ and $\mathrm{F})$. Bars with $\left({ }^{*}\right)$ differ at $(\mathrm{C}) P=0.04$, (E) $P=0.02$, (F) $P=0.01$.

primary antibodies served as negative controls. The nonspecific binding sites were blocked with either $10 \%$ horse serum or $10 \%$ normal goat serum, depending on the secondary antibody used in experiments. Peroxidase activity was detected using Liquid DAB + substrate kit (Dako Schweiz AG, Baar, CH, Switzerland). The sections were counterstained with hematoxylin and embedded in Histokit (Assistant, Osterode, Germany).

\section{In situ hybridization (ISH)}

According to the protocol described previously (Kowalewski et al. 2006b, Gram et al. 2013a), nonradioactive ISH on paraffin-embedded sections was carried out in order to investigate the uterine cellular localization of IGF1 and IGF2 at the mRNA level.

PCR products generated with the following primers were used for subsequent synthesis of the digoxigenin (DIG)-labeled CRNA probes: IGF1 forward: 5'-GGT GGA CGC TCT TCA GTT C-3', reverse: 5'-TCC TGC ACT CCC TCT ACT TG-3' (product length $268 \mathrm{bp}$, annealing temperature $60^{\circ} \mathrm{C}$ ) and IGF2 forward: 5'-GTG CTG CTT TGC TGC TTA C-3', reverse: 5'-GGG TAT CTG GGG AAG TTG TC-3' (product length $251 \mathrm{bp}$, annealing temperature $60^{\circ} \mathrm{C}$ ). The DIG-labeled cRNA was detected using alkaline phosphatase-conjugated sheep anti-DIG Fab Fragments (Roche Diagnostics) at 1:5000 dilution in $1 \%$ ovine serum, according to the manufacturer's instructions. Signals were detected with the substrate 5-bromo4-chloro-3-indolyl phosphate and nitroblue tetrazolium (NBT/BCIP; Roche Diagnostics).

\section{Results}

\section{Temporal expression of selected genes in canine uterine tissues during the pre-implantation stage of pregnancy}

Expression of several genes, as listed in Table 1, was investigated at both the mRNA and protein levels in the uteri of early-pregnant animals (pre-implantation) and compared with their expression in the corresponding tissues from nonpregnant dogs (nonpregnant controls).

Expression of all the selected genes was detectable in tissue samples obtained from early-pregnant and nonpregnant dogs. A significantly higher expression of IGF2 and $P R L R$ mRNA was observed in the early-pregnant uterus ( $P=0.04$ and $P=0.02$ respectively) compared with the controls (Fig. 1). The opposite effect was observed for the uterine expression of $L H R$, which was significantly downregulated during early pregnancy $(P=0.01)$ (Fig. 1). However, the expression of IGF1, IGF1R and PRL mRNA remained unaffected $(P=0.5, P=0.47$ and $P=0.42$ respectively) by uterine exposure to embryos (Fig. 1). In addition, $P R L$ mRNA was generally expressed at a very low level, and was frequently below the detection limit in both groups of animals.

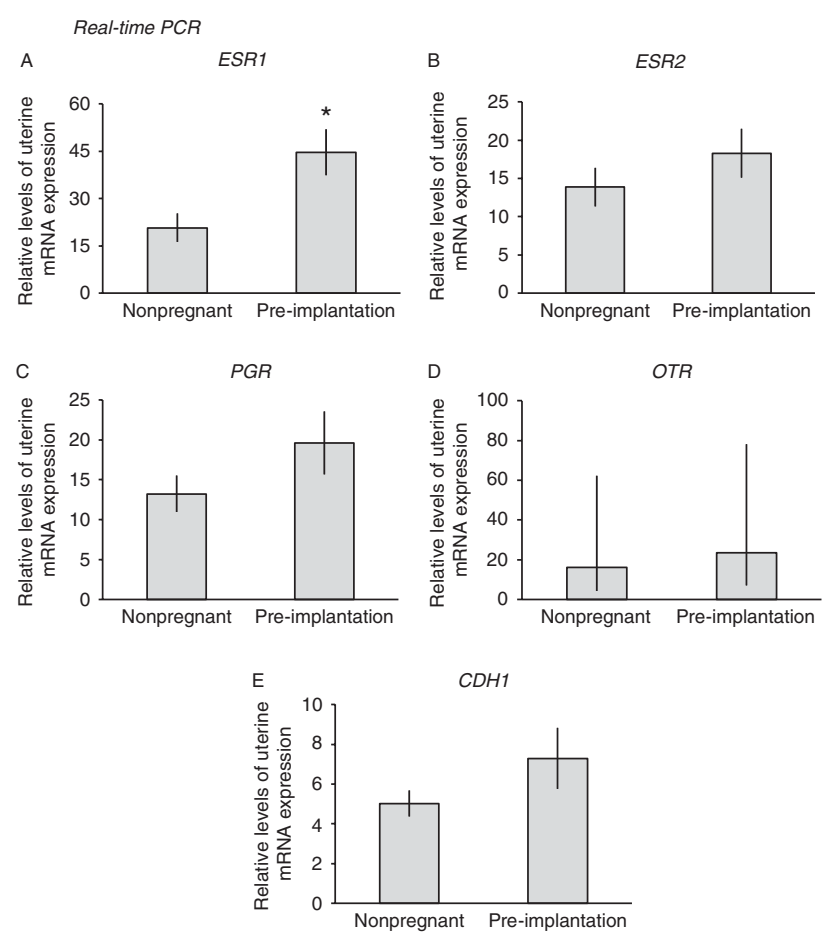

Figure 2 Expression of ESR1, ESR2, PGR, OXTR, and $C D H 1$ as determined by Real Time (TaqMan) PCR in uterine samples from earlypregnant uterus (pre-implantation; embryo-induced effects), and its nonpregnant counterparts. Numerical data are presented either as the mean \pm s.D. $(A, B, C$, and $E$ ), or as geometric means with deviation factor $\left(\mathrm{Xg} . \mathrm{DF}^{ \pm} 1\right)(\mathrm{D})$. Bar with $\left(^{*}\right)$ in $(\mathrm{A})$ differs at: $P=0.03$. 

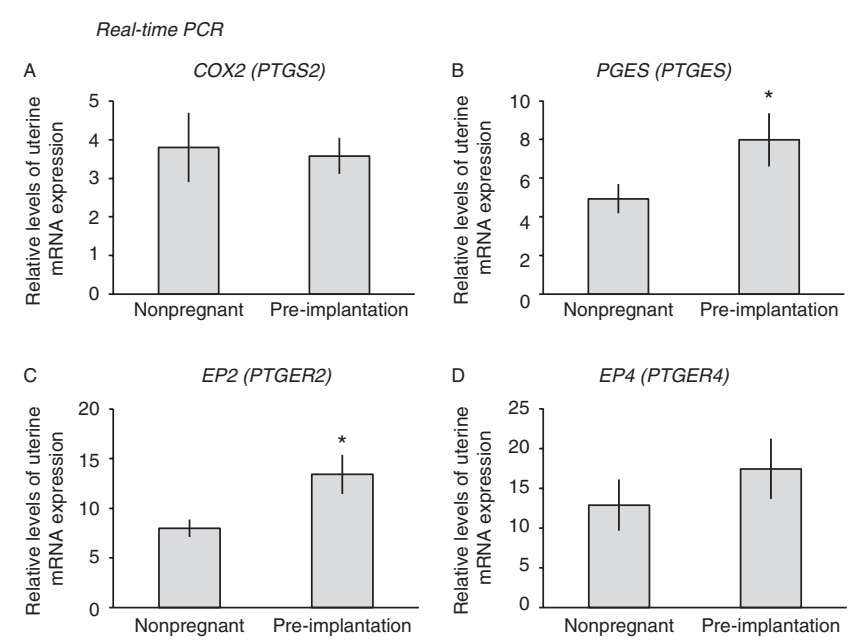

Figure 3 Expression of prostaglandin-endoperoxide synthase 2 (PTGS2, COX2), prostaglandin E2 (PGE2)-synthase (PTGES) and of PGE2 receptors, PTGER2 and PTGER4 as determined by Real Time (TaqMan) PCR in uterine samples from early-pregnant uterus (pre-implantation; embryo-induced effects), and its nonpregnant counterparts. Numerical data are presented as the mean \pm s.D. Bars with $\left(^{*}\right)$ differ at: (B) $P=0.04$, (C) $P=0.02$.

Among the steroid hormone receptors, only the expression of estrogen receptor $\alpha$ (ESR1) was significantly $(P=0.03)$ elevated in the early-pregnant uterus (Fig. 2), while expression of the $P G R$ and of ESR2 did not differ between the two groups $(P=0.27$ and $P=0.23$ respectively). Similarly, expression of the OTR, which varied widely among individuals in both groups, was unaffected $(P=0.5)$ by the reproductive status of the animals. The expression of $C D H 1$ did not differ $(P=0.25)$.

Concerning the expression of the major members of the PG system, no statistically significant differences were observed for the expression of mRNA encoding for the prostaglandin-endoperoxide synthase 2 (PTGS2, formerly known as COX2) $(P=0.8)$, the PGE2 receptor designated as PGER4 $(P=0.21)$, and 15 -hydroxy prostaglandin dehydrogenase $(H P G D)(P=0.29)$ (Figs 3A, D, and 4D). In contrast, a significant upregulation was noted for mRNA expression of PGE2-synthase PTGES $(P=0.04)$ and $A K R 1 B 3(P=0.007)$, as well as of their respective receptors, PTGER2 $(P=0.02)$ and PTGFR $(P=0.02)$ and of the PG-transporter $(P G T)(P=0.02)$, in the pre-implantation uterus compared with nonpregnant uterus (Figs 3B, C, and 4A, B, C).

\section{Localization of gene expression}

In the pre-implantation uterus, IHC clearly localized IGF2 protein expression to the surface epithelial cells and to the epithelial cells of the superficial and deep uterine glands; clearly detectable signals were also localized in the myometrium. Weaker signals were observed in the endometrial stroma (Fig. 5B and C). No, or only very weak IHC signals were observed for IGF2 expression in the uteri of nonpregnant dogs (Fig. 5A). A localization pattern similar to this but in both early-pregnant and nonpregnant uteri was observed at the mRNA level by using ISH (Fig. $5 \mathrm{H}$ and I). As also determined by ISH, IGF1 expression was co-localized with uterine IGF2 expression (Fig. 5F and G). There was no anti-IGF1 canine-specific antibody available for the IHC studies. The IGF1R protein expression followed the IGF1 and IGF2 distribution pattern with stronger signals observed in the early-pregnant uterus (Fig. 5D and E).

While weaker endometrial signals were observed for PRLR protein expression in the nonpregnant animals (Fig. 6A and B), stronger signals were detected in the surface and glandular endometrial epithelial cells of the early-pregnant uterus (Fig. 6C and D). Clear myometrial staining was noted in both groups of animals (Fig. 6B and D).

Expression of PGR was detectable in the uteri of both early-pregnant and control animals but did not vary widely between the two groups. The IHC signals were localized to the nuclei of both superficial and glandular epithelial cells, as well as the smooth muscle cells of the myometrium and to a lesser extent in the endometrial stroma (Fig. 7A and B).

The ESR1 protein was co-localized with PGR; however, signals were distinctly stronger in the uteri after exposure to embryos than in the nonpregnant controls (Fig. 7C and D). Much weaker staining was observed for uterine ESR2 expression which did not differ between the two groups and showed a similar localization pattern as for the other nuclear receptors (Fig. 7E and F).

Whereas endometrium stained negatively for COX2, myometrial signals were strong (Fig. 8A), but no or only
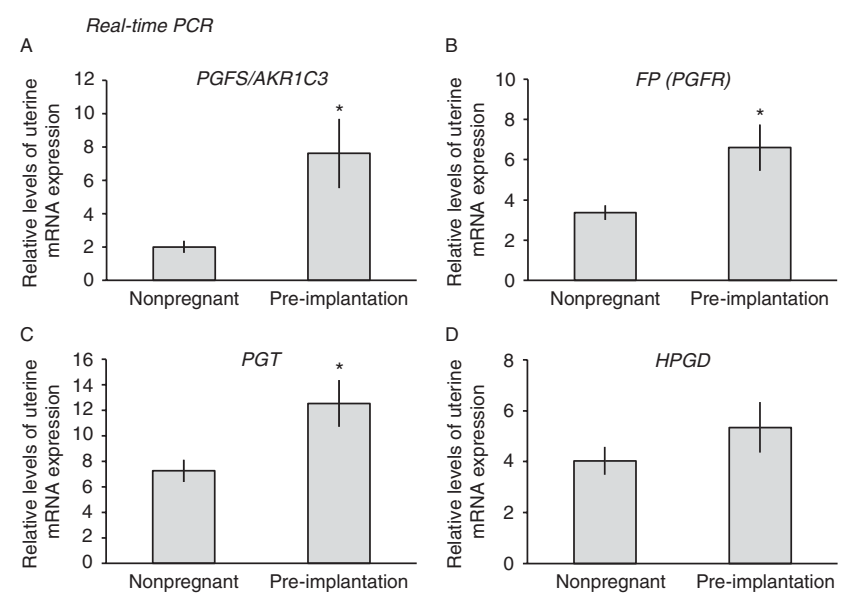

Figure 4 Expression of (A) prostaglandin $\mathrm{F} 2 \alpha(\mathrm{PGF} 2 \alpha)$-synthase (AKR1C3), (B) PGF2 $\alpha$-receptor (FP, PTGFR), (C) prostaglandin transporter $(P G T)$ and of (D) 15-prostaglandin dehydrogenase (HPGD) as determined by Real Time (TaqMan) PCR in uterine samples from early-pregnant uterus (pre-implantation; embryo-induced effects), and its nonpregnant counterparts. Numerical data are presented as the mean \pm s.D. Bars with $\left(^{*}\right)$ differ at (A) $P=0.007$, (B) $P=0.02$, (C) $P=0.02$. 

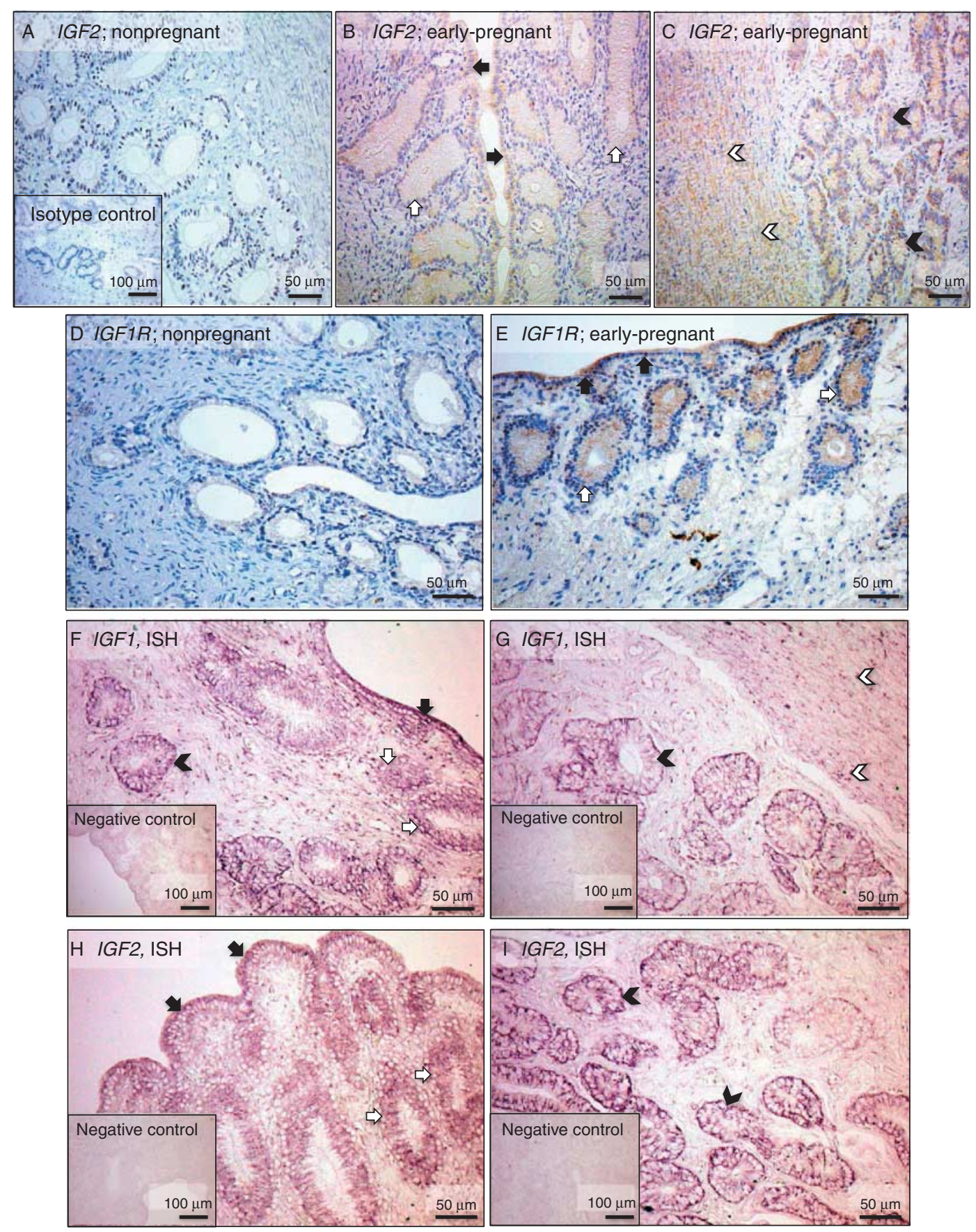

Figure 5 IHC localization of IGF2 (A, B, and C) and IGF1R (D and E), in early-pregnant (pre-implantation) canine uterus and corresponding nonpregnant uterus. The localization of IGF1 (F and G) and IGF2 ( $\mathrm{H}$ and I) mRNA expression is presented by in situ hybridization (ISH). Solid arrows, superficial (luminal) uterine epithelium; open arrows, superficial uterine glands; solid arrowheads, deep uterine glands; open arrowheads, myometrium. The inset to (A) shows a representative IgG isotype control for anti-rabbit immune serum.

very weak uterine signals were observed for AKR1C3 protein, in both groups of animals (Fig. 8B).

The expression of SLCO2A1, PTGES, PTGER2, and PTGER4 revealed a similar protein distribution pattern as that of PRLR, showing their co-localization and higher abundance in endometrial epithelial cells, the myometrium, and the stromal cells in the pre-implantation uterus (Figs 8C, D, and 9A, B, C, D, E, F). For all these factors, staining in the endometrial stroma was weaker than in the epithelial compartments. High variability for the HPGD IHC signals was observed between individual animals in both groups. They tended, however, to be stronger in the early-pregnant uteri and revealed a similar localization pattern, but with 

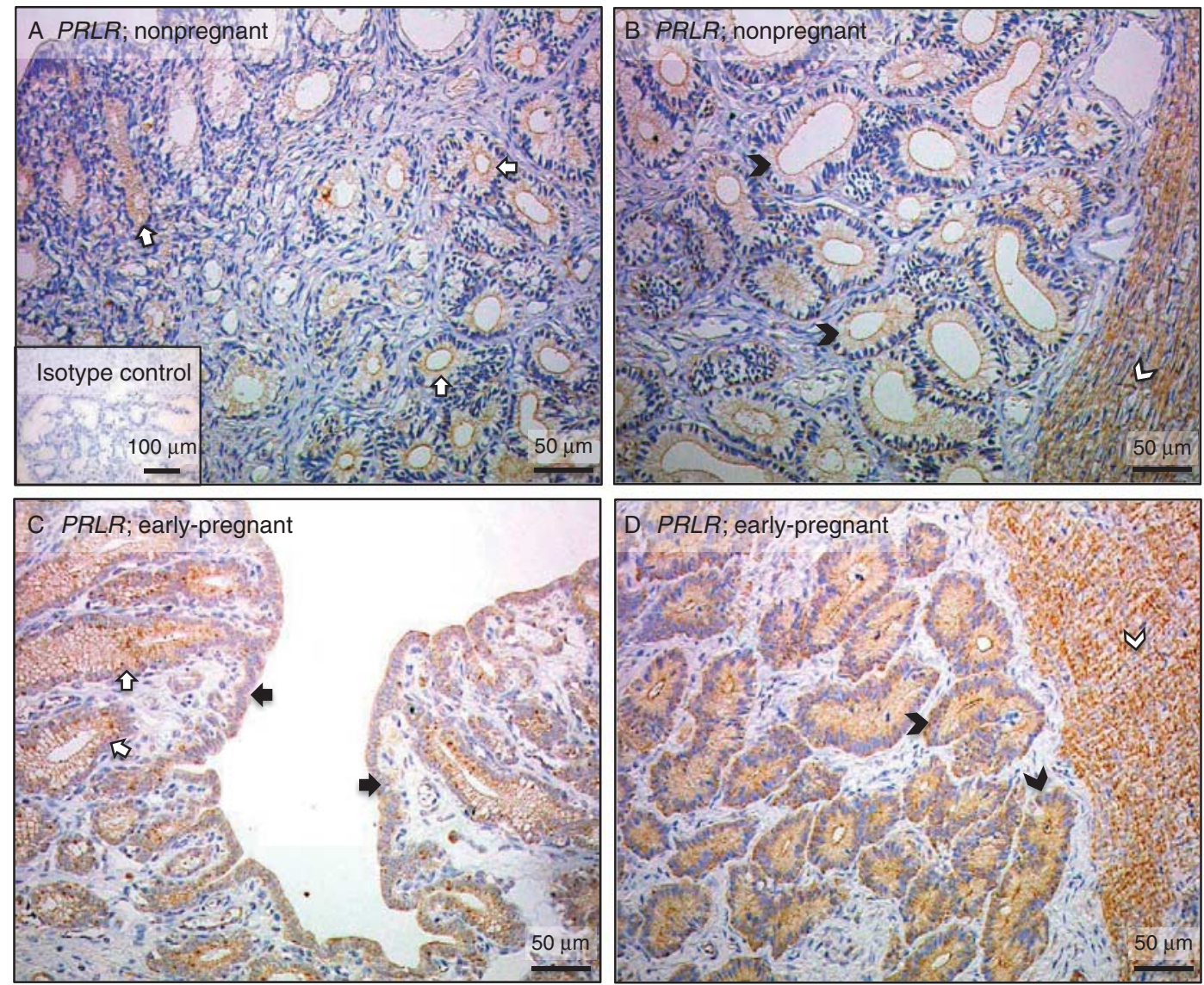

Figure 6 Immunohistochemical localization of $P R L R$ in early-pregnant (pre-implantation) canine uterus (C and D) and corresponding nonpregnant uterus (A and B). Solid arrows, superficial (luminal) uterine epithelium; open arrows, superficial uterine glands; solid arrowheads, deep uterine glands; open arrowheads, myometrium. The inset to (A) shows a representative IgG isotype control for anti-goat immune serum.

distinctly stronger staining in the deep uterine glands (Fig. 8E, F, and G).

\section{Expression of selected genes in early, free-floating canine embryos before implantation}

Due to the limited availability of the embryo material, investigations were restricted for detecting the expression of IGF1, IGF2, PTGS2, and PTGES in the two groups of embryos (unhatched and hatched blastocysts) collected from five early-pregnant bitches. Embryos were pooled in order to reach the required limits of detection. Consequently, no statistical analysis of gene expression was possible.

Whereas the expression of IGF1, IGF2, and PTGS2 mRNA was below the detection limit in the unhatched embryos, the PTGES mRNA was abundantly expressed and detectable in both unhatched and hatched blastocysts, with apparently higher expression level in the latter ones (Fig. 10A). The expression of IGF2 mRNA seemed to be higher than that of IGF1 mRNA in the group of hatched embryos (Fig. 10B), while PTGS2 and PTGES showed similar transcript abundance (Fig. 10C).

\section{Discussion}

The uterine response to early embryo exposure was investigated during the pre-implantation stage of canine pregnancy by measuring the expression of several target genes. Our investigations were based on the assumption that, in view of the lack of an anti-luteolytic signal in the dog resulting in similar hormonal status in earlypregnant and nonpregnant dioestric bitches, some local effects would be exerted by the early preimplantation embryos that modify the uterine milieu, serving as a prerequisite for a successful implantation and ensuring embryo survival before attachment. The effects of seminal plasma-derived bioactive factors in the modulation of the uterine endocrine milieu, and possibly having an impact on the initiation of pregnancy in dogs, were not separately investigated in this study, but would certainly merit future investigations.

Among the genes investigated, IGF1, IGF2, and PRL count as the most prominent and well-characterized markers of the decidualization process (Irwin et al. 1994, Ramathal et al. 2010). By interacting mainly with the IGF1R (Wang \& Chard 1999), both IGF1 and IGF2 are mitogenic factors whose uterine expression is regulated 

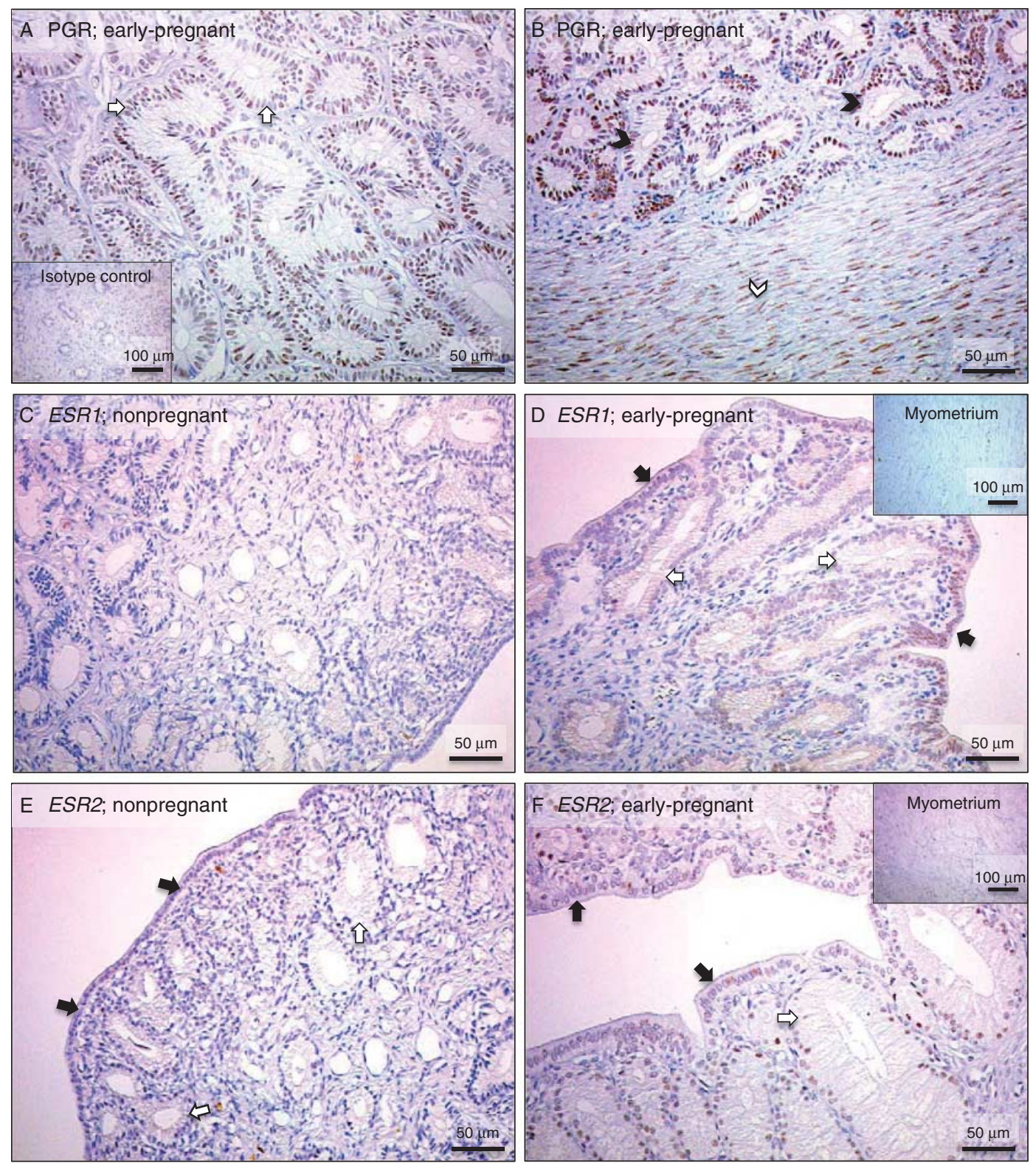

Figure 7 Immunohistochemical localization of PGR (A and B), ESR1 (C and D) and ESR2 (E and F) in early-pregnant (pre-implantation) canine uterus and corresponding nonpregnant uterus. Solid arrows, superficial (luminal) uterine epithelium; open arrows, superficial uterine glands; solid arrowheads, deep uterine glands, open arrowhead in (B) indicates myometrium. Insets to (D and F) show the myometrial expression of ESR1 and ESR2, respectively. The inset to (A) shows a representative $\lg G$ isotype control for anti-mouse immune serum.

by steroidogenic hormones (De Cock et al. 2002, Bhatti et al. 2007, Dantzer \& Swanson 2012). They possess differentiation properties capable of influencing embryonic development, as shown, e.g., in humans and ruminants (Wathes et al. 1998, Irwin et al. 1999, Kim et al. 2008). In addition, in human decidua, for example, IGF1 regulates PRL and arachidonic acid secretion (Handwerger et al. 1991), the latter serving as a common precursor for PG synthesis.

As for the early-pregnant canine uterus investigated in this study, only the expression of IGF2 was significantly upregulated. This was concomitant with the greater abundance of IGF2 transcripts in the hatched embryos collected at days 10-12 of canine pregnancy, suggesting the predominant role of IGF2 compared with IGF1, during this very early stage of pregnancy in the dog. In contrast to the unaffected IGF1R-mRNA expression levels, which varied widely among individuals, expression of the respective protein was clearly detectable and seemed to be more strongly expressed during early pregnancy, implying the involvement of posttranscriptional regulatory mechanisms in its expression.

The uterine expression of $P R L R$, but not of $\mathrm{PRL}$, was strongly upregulated after embryo exposure 

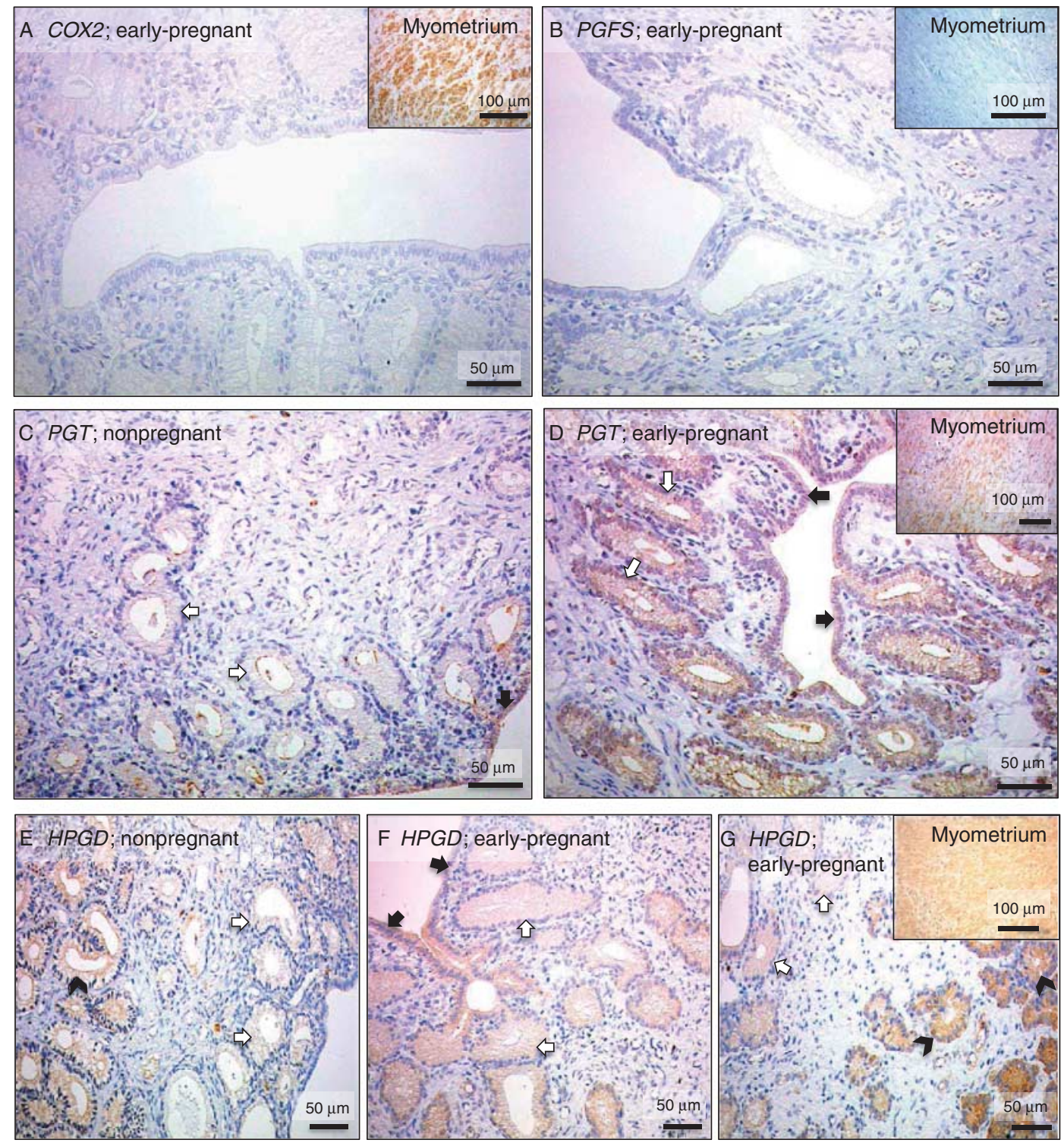

Figure 8 Immunohistochemical localization of COX2, (PTGS2) (A), PGFS/AKR1C3 (B) in early-pregnant (pre-implantation) canine and of PGT (C and $\mathrm{D})$ and $\operatorname{HPGD}(\mathrm{E}, \mathrm{F}$, and $\mathrm{G}$ ) in early pre-implantation uterus and corresponding nonpregnant uterus. Solid arrows, superficial (luminal) uterine epithelium; open arrows, superficial uterine glands; solid arrowheads, deep uterine glands. Insets in (A, B, D and G) show the myometrial expression of COX2, AKR1C3, SLCO2A1, and HPGD respectively.

pre-implantation. This finding agrees with our previous report about the uterine and placental expression of PRLR (Kowalewski et al. 2011a), implying the possible role of PRLR-mediated effects in endometrial glandular secretory activity during the production of uterine milk (histiotrophe), a mechanism that was also suggested for humans (Jabbour et al. 1998). Our previous observation that interfering with PGR function by applying an antigestagen results in a decreased utero/placental PRLR expression suggests that this involves progesteronemediated effects (Kowalewski et al. 2011a). In this study, although uterine $P R L$ expression was relatively low, and frequently even below the detection limit, possible paracrine effects of locally produced PRL cannot be ruled out. Its contribution to circulating $P R L$ levels does not seem, however, very likely. In contrast to $P R L R$ expression, the expression of $L H R$ was downregulated in the early-pregnant canine uterus. Recently, the role of $L H R$ was suggested as a possible important factor contributing to the implantation process in mice (Gridelet et al. 2013). While any final conclusion concerning LHR function during the onset of canine pregnancy would be premature, we believe that this warrants further investigations.

Besides acting as one of the most potent uterotonic hormones, oxytocin also regulates secretion of other 

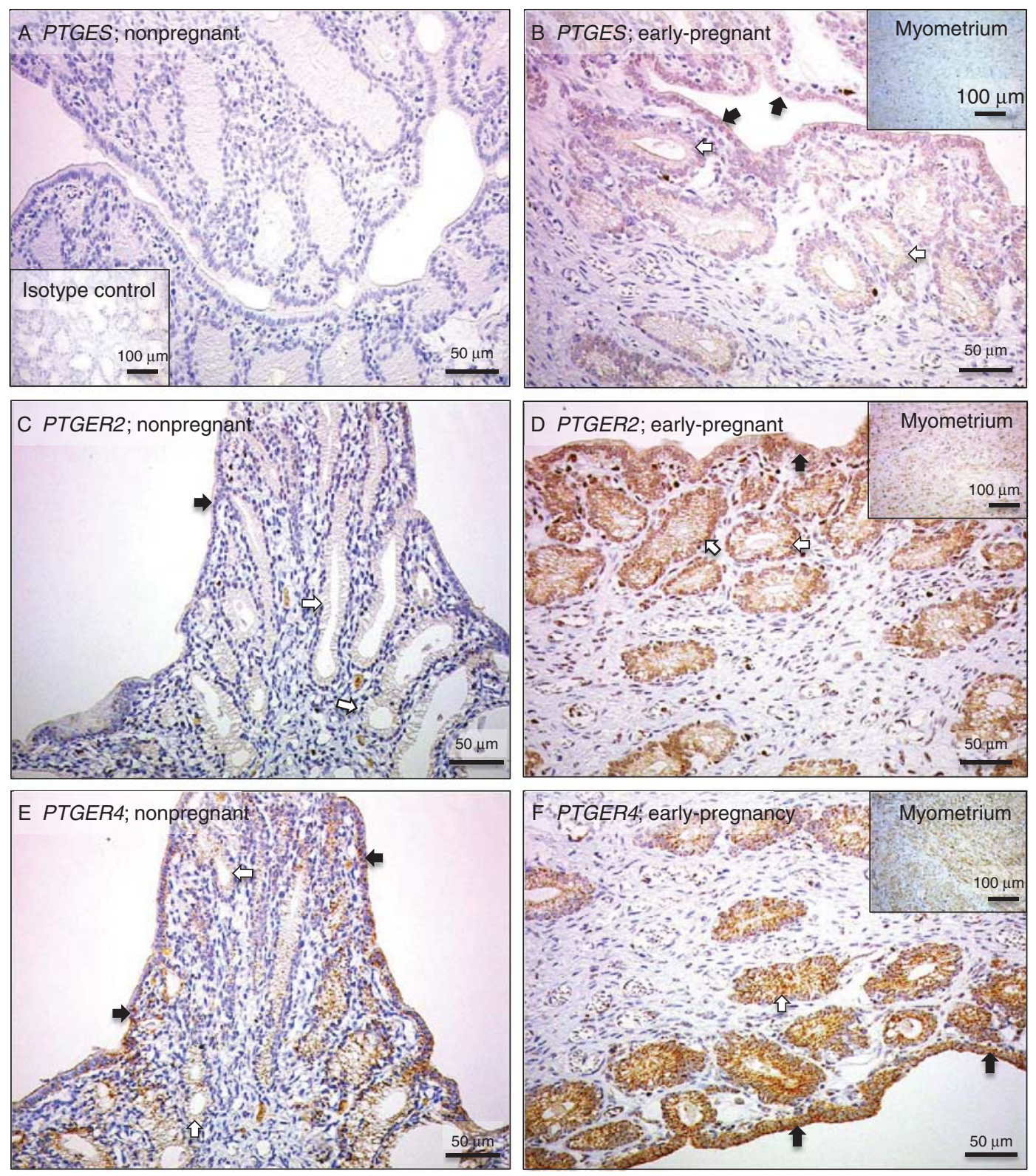

Figure 9 Immunohistochemical localization of prostaglandin E2-synthase (PGE2-synthase, PTGES) (A and B), PGE2-receptors PTGER2 and PTGER4 $(C$ and $D)$ and (E and F), respectively, in the early-pregnant (pre-implantation) canine uterus and corresponding nonpregnant uterus. Solid arrows, superficial (luminal) uterine epithelium; open arrows, uterine glands. Insets to (B, D, and F) show the myometrial expression of PTGES, PTGER2 and PTGER4, respectively. The inset to (A) shows a representative IgG isotype control for anti-guinea pig immune serum.

hormones, e.g., PGs (Meier et al. 1995, Fuchs et al. 1999). This prompted us to investigate the expression of the OTR in the early-pregnant uterus and its corresponding nonpregnant counterpart. Most recently we have localized OTR to the uterine surface epithelium of the pre-implantation uterus, specifically in the superficial and deep glands and the vascular endothelial and stromal cells (Gram et al. 2013b). In this study, however, OTR expression varied widely among individuals and, consequently, did not differ significantly between the two groups, thereby not allowing any further conclusions to be drawn regarding its potential secretory or constrictory activity during the onset of canine pregnancy. Such activity could relate, e.g., to mechanisms involved in the distribution and positioning of freefloating embryos before attachment, or to the role of oxytocin as a mediator of local PG effects.

The expression of PTGS2, the rate-limiting factor in the provision of PGs, and of AKR1C3 protein, was low in the early dioestric uterus and remained unaffected by the presence of embryos. The AKR1C3 is the only caninespecific isoform of PGFS known to date and is responsible for the direct conversion of $\mathrm{PGH} 2$ to PGF2 $\alpha$ (Gram et al. 2013a). As the expression of the 

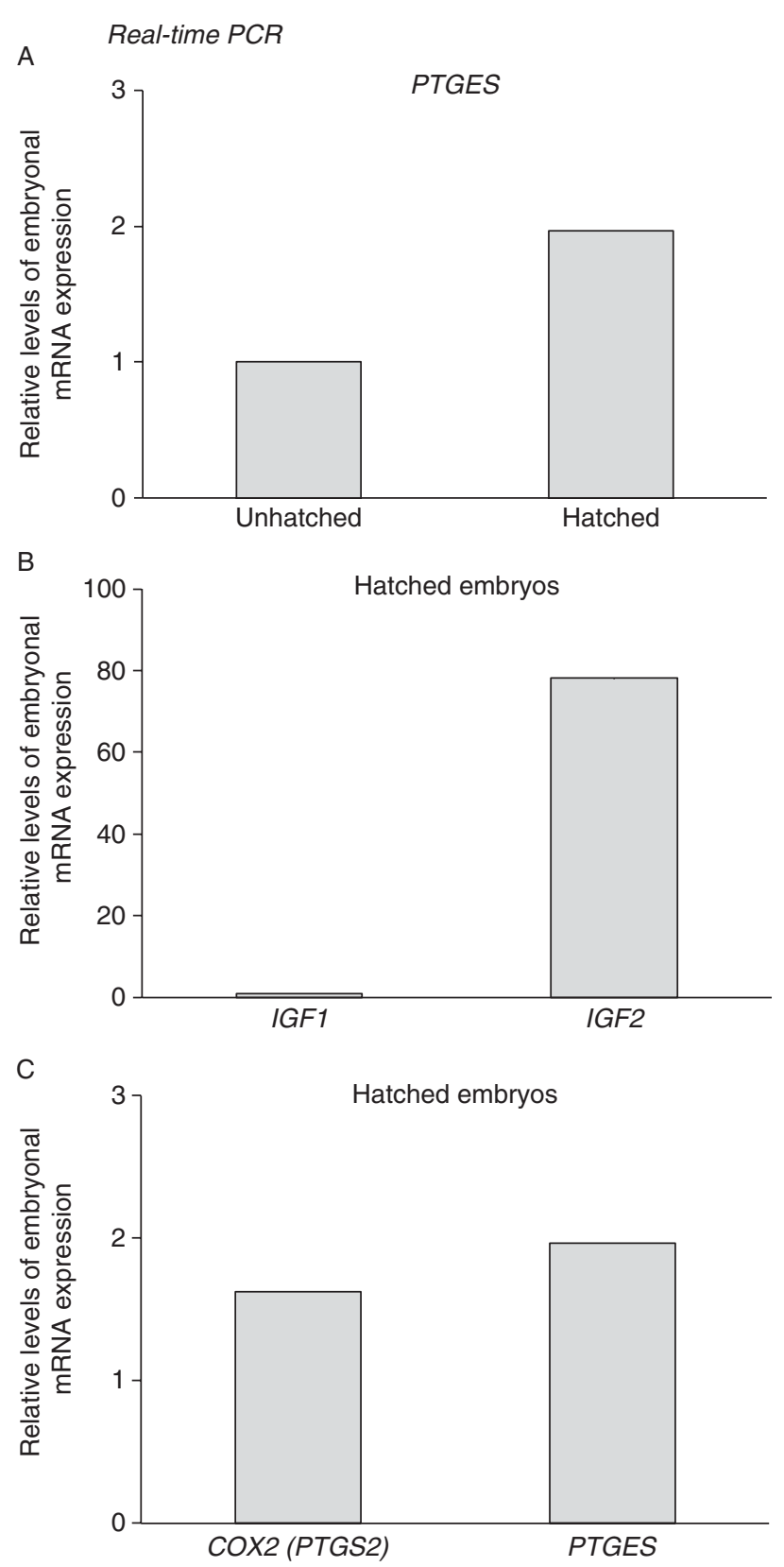

Figure 10 Embryonal expression of prostaglandin E2-synthase (PTGES), cyclooxygenase 2 (PTGS2), insulin-like growth factor 1 (IGF1) and IGF2 as determined by Real Time (TaqMan) PCR.

respective mRNA was significantly increased in early pregnancy, some local effects and possible involvement of posttranscriptional regulatory mechanisms cannot be excluded, especially in view of the concomitantly increased expression of the PGF2 $\alpha$-receptor (PTGFR). In contrast, the expression of PTGES was significantly affected both at the mRNA and protein levels in response to early embryo exposure, which together with the upregulated expression of SLCO2A1 further implies local effects of PGs. This conclusion also agrees with our previous report suggesting a role of PGs in canine decidualization, placentation and, later on, in trophoblast invasion (Kowalewski et al. 2010, Gram et al. 2013a). The low levels of PTGS2 expression, together with clearly detectable uterine HPGD expression (the enzyme responsible for conversion of PGE2 and PGF2 $\alpha$ to their inactive metabolites) in pregnant and nonpregnant uteri, could additionally coordinate and restrict the effects of PGs as local regulatory factors.

By acting through its two G-protein-coupled receptors designated as PTGER2 and PTGER4, PGE2 exerts its roles mostly through the CAMP/PKA signaling pathway (Christenson et al. 1994, Boiti et al. 2001, Harris et al. 2001, Arosh et al. 2004). Also, progesterone-dependent decidualization is CAMP-mediated and this process is accelerated by PGE2 in human endometrial stromal cells (Brar et al. 1997). Similar effects of PGE2 and its potential to stimulate the decidual cell reaction were observed in rats (Kennedy \& Doktorcik 1988). This could also be true for the canine species, as indicated in the present study by the increased uterine synthesis of PTGES, PTGER2, and also PTGER4 protein, concomitant with the higher PTGES expression in the hatched embryos, possibly actively contributing to the decidualization process.

It is noteworthy that in the uterine samples investigated in this study, derived from both early-pregnant and nonpregnant bitches, stronger IHC signals were localized in the endometrial epithelial compartments. On the other hand, weaker signals were observed in the uterine stromal cells that undergo a strong, speciesspecific decidualization process later on in canine gestation. This, together with the unaffected IGF1 and strongly varying IGF1R mRNA expression in the preimplantation uterus, seems to be an indicator of the early stage of uterine differentiation at the beginning of pregnancy (gestational days 10-12) observed in our study. At this time, the uterine morphology is characterized by obvious embryo-induced functional changes reflected in the modified uterine milieu observed here, but does not yet exhibit the very strong structural changes related to the intense remodeling of uterine tissues that occur later in gestation, especially during decidua formation at the implantation sites. This is also indicated by the unaffected expression of $\mathrm{CDH}$.

Taken together with some earlier studies, our investigations describe the expression of genes that are differentially regulated in response to the presence of free-floating embryos in the uterine lumen of earlypregnant dogs and provide a basis for better understanding of the uterine milieu required for proper embryo development and, thereby, for successful establishment of canine pregnancy. Elucidating possible functional interactions between these factors, e.g., their role in uterine growth and secretory activity, could be helpful in understanding some pathological conditions connected with dysregulated endocrinological responses of the 
uterus, which are frequently caused by impaired crosstalk between growth factors and hormones.

\section{Declaration of interest}

The authors declare that there is no conflict of interest that could be perceived as prejudicing the impartiality of the research reported.

\section{Funding}

The research work was supported by The Swiss National Science Foundation (SNSF) grant number 31003A_140947 to MPK.

\section{Acknowledgements}

The authors are grateful to Dr Barry Bavister for careful editing of the manuscript. The technical expertise and contributions of Elisabeth Högger and Stefanie Ihle are gratefully appreciated.

\section{References}

Amoroso EC 1952 Placentation. In Marshall's Physiology of Reproduction, pp 127-316.

Arosh JA, Banu SK, Chapdelaine P, Madore E, Sirois J \& Fortier MA 2004 Prostaglandin biosynthesis, transport, and signaling in corpus luteum: a basis for autoregulation of luteal function. Endocrinology 145 2551-2560. (doi:10.1210/en.2003-1607)

Baan M, Taverne MA, de Gier J, Kooistra HS, Kindahl H, Dieleman SJ \& Okkens AC 2008 Hormonal changes in spontaneous and aglepristoneinduced parturition in dogs. Theriogenology 69 399-407. (doi:10.1016/ j.theriogenology.2007.10.008)

Beceriklisoy HB, Schafer-Somi S, Kucukaslan I, Agaoglu R, Gultiken N, Ay SS, Kaya D \& Aslan S 2009 Cytokines, growth factors and prostaglandin synthesis in the uterus of pregnant and non-pregnant bitches: the features of placental sites. Reproduction in Domestic Animals 44 (Suppl 2) 115-119. (doi:10.1111/j.1439-0531.2009.01443.x)

Bhatti SF, Rao NA, Okkens AC, Mol JA, Duchateau L, Ducatelle R, van den Ingh TS, Tshamala M, Van Ham LM, Coryn M et al. 2007 Role of progestin-induced mammary-derived growth hormone in the pathogenesis of cystic endometrial hyperplasia in the bitch. Domestic Animal Endocrinology 33 294-312. (doi:10.1016/j.domaniend.2006.06.005)

Boiti C, Zampini D, Zerani M, Guelfi G \& Gobbetti A 2001 Prostaglandin receptors and role of $\mathrm{G}$ protein-activated pathways on corpora lutea of pseudopregnant rabbit in vitro. Journal of Endocrinology 168 141-151. (doi:10.1677/joe.0.1680141)

Brar AK, Frank GR, Kessler CA, Cedars MI \& Handwerger S 1997 Progesterone-dependent decidualization of the human endometrium is mediated by cAMP. Endocrine 6 301-307. (doi:10.1007/BF02820507)

Buhi WC, Shille VM, Thatcher MJ, Alvarez IM \& Qiu YX 1993 Identification and immunolocalization of proteins synthesized by dog endometrium and membranes. Journal of Reproduction and Fertility. Supplement $\mathbf{4 7}$ 141-157.

Bukowska D, Kempisty B, Jackowska M, Wozna M, Antosik P, Piotrowska H \& Jaskowski JM 2011 Analysis of integrins and vascular endothelial growth factor isoforms mRNA expression in the canine uterus during perimplantation period. Polish Journal of Veterinary Sciences $\mathbf{1 4}$ 253-258.

Christenson LK, Farley DB, Anderson LH \& Ford SP 1994 Luteal maintenance during early pregnancy in the pig: role for prostaglandin E2. Prostaglandins 47 61-75. (doi:10.1016/0090-6980(94)90075-2)

Concannon P 1980 Effects of hypophysectomy and of LH administration on luteal phase plasma progesterone levels in the beagle bitch. Journal of Reproduction and Fertility 58 407-410. (doi:10.1530/jrf.0.0580407)
Concannon PW, McCann JP \& Temple M 1989 Biology and endocrinology of ovulation, pregnancy and parturition in the dog. Journal of Reproduction and Fertility. Supplement 39 3-25.

Concannon PW, Gimpel T, Newton L \& Castracane VD 1996 Postimplantation increase in plasma fibrinogen concentration with increase in relaxin concentration in pregnant dogs. American Journal of Veterinary Research 57 1382-1385.

Dantzer B \& Swanson EM 2012 Mediation of vertebrate life histories via insulin-like growth factor-1. Biological Reviews of the Cambridge Philosophical Society 87 414-429. (doi:10.1111/j.1469-185X.2011. 00204.x)

De Cock H, Ducatelle R, Tilmant K \& De Schepper J 2002 Possible role for insulin-like growth factor-I in the pathogenesis of cystic endometrial hyperplasia pyometra complex in the bitch. Theriogenology $\mathbf{5 7}$ 2271-2287. (doi:10.1016/S0093-691X(02)00856-7)

Evans JM \& Anderton DJ 1992 Pregnancy diagnosis in the bitch: the development of a test based on the measurement of acute phase proteins in the blood. Annales De Zootechnie 41 397-405. (doi:10.1051/ animres:19920321)

Fuchs AR, Rust W \& Fields MJ 1999 Accumulation of cyclooxygenase-2 gene transcripts in uterine tissues of pregnant and parturient cows: stimulation by oxytocin. Biology of Reproduction 60 341-348. (doi:10. 1095/biolreprod60.2.341)

Gram A, Buechler U, Boos A, Hoffmann B \& Kowalewski MP 2013 a Biosynthesis and degradation of canine placental prostaglandins: prepartum changes in expression and function of prostaglandin $\mathrm{F} 2 \alpha-$ synthase (PGFS, AKR1C3) and 15-hydroxyprostaglandin dehydrogenase (HPGD). Biology of Reproduction 89 2. (doi:10.1095/biolreprod.113. 109918)

Gram A, Boos A \& Kowalewski M 2013b Uterine and placental expression of canine oxytocin receptor (OTR) during pregnancy and normal and induced parturition. In Proceedings for 16th EVSSAR Congress, pp 111.

Gridelet V, Tsampalas M, Berndt S, Hagelstein MT, Charlet-Renard C, Conrath V, Ectors F, Huge F, Munaut C, Foidart JM et al. 2013 Evidence for cross-talk between the $\mathrm{LH}$ receptor and $\mathrm{LH}$ during implantation in mice. Reproduction, Fertility, and Development 25 511-522. (doi:10. 1071/RD11241)

Handwerger S, Markoff E \& Richards R 1991 Regulation of the synthesis and release of decidual prolactin by placental and autocrine/paracrine factors. Placenta 12 121-130. (doi:10.1016/0143-4004(91)90016-9)

Harris TE, Squires PE, Michael AE, Bernal AL \& Abayasekara DR 2001 Human granulosa-lutein cells express functional EP1 and EP2 prostaglandin receptors. Biochemical and Biophysical Research Communications 285 1089-1094. (doi:10.1006/bbrc.2001.5301)

Hoffmann B, Hoveler R, Hasan SH \& Failing K 1992 Ovarian and pituitary function in dogs after hysterectomy. Journal of Reproduction and Fertility 96 837-845. (doi:10.1530/jrf.0.0960837)

Hoffmann B, Hoveler R, Nohr B \& Hasan SH 1994 Investigations on hormonal changes around parturition in the dog and the occurrence of pregnancy-specific non conjugated oestrogens. Experimental and Clinical Endocrinology 102 185-189. (doi:10.1055/s-0029-1211280)

Irwin JC, de las Fuentes L \& Giudice LC 1994 Growth factors and decidualization in vitro. Annals of the New York Academy of Sciences 734 7-18. (doi:10.1111/j.1749-6632.1994.tb21730.x)

Irwin JC, Suen LF, Martina NA, Mark SP \& Giudice LC 1999 Role of the IGF system in trophoblast invasion and pre-eclampsia. Human Reproduction 14 (Suppl 2) 90-96. (doi:10.1093/humrep/14.suppl_2.90)

Jabbour HN, Critchley HO \& Boddy SC 1998 Expression of functional prolactin receptors in nonpregnant human endometrium: janus kinase-2, signal transducer and activator of transcription-1 (STAT1), and STAT5 proteins are phosphorylated after stimulation with prolactin. Journal of Clinical Endocrinology and Metabolism 83 2545-2553. (doi:10.1210/ jcem.83.7.4989)

Kennedy TG \& Doktorcik PE 1988 Effects of analogues of prostaglandin E2 and F2 $\alpha$ on the decidual cell reaction in the rat. Prostaglandins 35 207-219. (doi:10.1016/0090-6980(88)90088-3)

Kim J, Song G, Gao H, Farmer JL, Satterfield MC, Burghardt RC, Wu G, Johnson GA, Spencer TE \& Bazer FW 2008 Insulin-like growth factor II activates phosphatidylinositol 3-kinase-protooncogenic protein kinase 1 and mitogen-activated protein kinase cell signaling pathways, and stimulates migration of ovine trophectoderm cells. Endocrinology 149 3085-3094. (doi:10.1210/en.2007-1367) 
Kowalewski MP, Schuler G, Taubert A, Engel E \& Hoffmann B 2006a Expression of cyclooxygenase 1 and 2 in the canine corpus luteum during diestrus. Theriogenology 66 1423-1430. (doi:10.1016/j.theriogenology.2006.01.039)

Kowalewski MP, Mason JI, Howie AF, Morley SD, Schuler G \& Hoffmann B $2006 b$ Characterization of the canine $3 \beta$-hydroxysteroid dehydrogenase and its expression in the corpus luteum during diestrus. Journal of Steroid Biochemistry and Molecular Biology 101 254-262. (doi:10.1016/ j.jsbmb.2006.06.029)

Kowalewski MP, Mutembei HM \& Hoffmann B 2008 Canine prostaglandin E2 synthase (PGES) and its receptors (EP2 and EP4): expression in the corpus luteum during dioestrus. Animal Reproduction Science 109 319-329. (doi:10.1016/j.anireprosci.2007.11.023)

Kowalewski MP, Beceriklisoy HB, Aslan S, Agaoglu AR \& Hoffmann B 2009 Time related changes in luteal prostaglandin synthesis and steroidogenic capacity during pregnancy, normal and antiprogestin induced luteolysis in the bitch. Animal Reproduction Science 116 129-138. (doi:10.1016/ j.anireprosci.2008.12.011)

Kowalewski MP, Beceriklisoy HB, Pfarrer C, Aslan S, Kindahl H, Kucukaslan I \& Hoffmann B 2010 Canine placenta: a source of prepartal prostaglandins during normal and antiprogestin-induced parturition. Reproduction 139 655-664. (doi:10.1530/REP-09-0140)

Kowalewski MP, Michel E, Gram A, Boos A, Guscetti F, Hoffmann B, Aslan S \& Reichler I 2011a Luteal and placental function in the bitch: spatio-temporal changes in prolactin receptor (PRLr) expression at dioestrus, pregnancy and normal and induced parturition. Reproductive Biology and Endocrinology 9 109. (doi:10.1186/1477-7827-9-109)

Kowalewski MP, Meyer A, Hoffmann B, Aslan S \& Boos A 2011 b Expression and functional implications of peroxisome proliferator-activated receptor $\gamma(\mathrm{PPAR} \gamma)$ in canine reproductive tissues during normal pregnancy and parturition and at antiprogestin induced abortion. Theriogenology 75 877-886. (doi:10.1016/j.theriogenology.2010.10.030)

Kowalewski MP, Fox B, Gram A, Boos A \& Reichler I 2013 Prostaglandin E2 functions as a luteotrophic factor in the dog. Reproduction 145 213-226. (doi:10.1530/REP-12-0419)

Luvoni GC, Chigioni S \& Beccaglia M 2006 Embryo production in dogs: from in vitro fertilization to cloning. Reproduction in Domestic Animals 41 286-290. (doi:10.1111/j.1439-0531.2006.00704.x)

Meier S, Lau TM, Jenkin G \& Fairclough RJ 1995 Oxytocin-induced prostaglandin F2 $\alpha$ release and endometrial oxytocin receptor concentrations throughout pregnancy in ewes. Journal of Reproduction and Fertility 103 233-238. (doi:10.1530/jrf.0.1030233)

Nohr B, Hoffmann B \& Steinetz BE 1993 Investigation of the endocrine control of parturition in the dog by application of an antigestagen. Journal of Reproduction and Fertility. Supplement 47 542-543.
Okkens AC, Dieleman SJ, Bevers MM, Lubberink AA \& Willemse AH 1986 Influence of hypophysectomy on the lifespan of the corpus luteum in the cyclic dog. Journal of Reproduction and Fertility 77 187-192. (doi:10.1530/jrf.0.0770187)

Okkens AC, Bevers MM, Dieleman SJ \& Willemse AH 1990 Evidence for prolactin as the main luteotrophic factor in the cyclic dog. Veterinary Quarterly 12 193-201. (doi:10.1080/01652176.1990.9694266)

Olson PN, Bowen RA, Behrendt MD, Olson JD \& Nett TM 1984 Concentrations of progesterone and luteinizing hormone in the serum of diestrous bitches before and after hysterectomy. American Journal of Veterinary Research 45 149-153.

Onclin K, Silva LD, Donnay I \& Verstegen JP 1993 Luteotrophic action of prolactin in dogs and the effects of a dopamine agonist, cabergoline. Journal of Reproduction and Fertility. Supplement 47 403-409.

Onclin K, Verstegen JP \& Concannon PW 2000 Time-related changes in canine luteal regulation: in vivo effects of $\mathrm{LH}$ on progesterone and prolactin during pregnancy. Journal of Reproduction and Fertility 118 417-424.

Ramathal CY, Bagchi IC, Taylor RN \& Bagchi MK 2010 Endometrial decidualization: of mice and men. Seminars in Reproductive Medicine 28 17-26. (doi:10.1055/s-0029-1242989)

Schafer-Somi S, Beceriklisoy HB, Budik S, Kanca H, Aksoy OA, Polat B, Cetin Y, Ay SS \& Aslan S 2008 Expression of genes in the canine preimplantation uterus and embryo: implications for an active role of the embryo before and during invasion. Reproduction in Domestic Animals 43 656-663. (doi:10.1111/j.1439-0531.2007.00966.x)

Vermeirsch H, Simoens P \& Lauwers H 2000 Immunohistochemical detection of the estrogen receptor- $\alpha$ and progesterone receptor in the canine pregnant uterus and placental labyrinth. Anatomical Record 260 42-50. (doi:10.1002/1097-0185(20000901)260:1<42::AID-AR50 $>3.0 . \mathrm{CO} ; 2-8)$

Wang HS \& Chard T 1999 IGFs and IGF-binding proteins in the regulation of human ovarian and endometrial function. Journal of Endocrinology 161 1-13. (doi:10.1677/joe.0.1610001)

Wathes DC, Reynolds TS, Robinson RS \& Stevenson KR 1998 Role of the insulin-like growth factor system in uterine function and placental development in ruminants. Journal of Dairy Science 81 1778-1789. (doi:10.3168/jds.S0022-0302(98)75747-9)

Received 6 December 2013

First decision 8 January 2014

Revised manuscript received 17 January 2014

Accepted 30 January 2014 